\title{
'The trouble with sex - it always gets in the way': An evaluation of a peer-produced teenage pregnancy video
}

\author{
Anne Pedrazzini, MB ChB, Senior Clinical Medical Officer; Heather McGowan, PEV Co-ordinator, Linda Lucking, \\ Clinical Trials Co-ordintor, Richard Johanson, MD, MRCOG, Consultant Obstetrician and Gynaecologist \\ Academic Department of Obstetrics and Gynaecology, North Staffordshire Hospital NHS Trust, UK
}

Correspondence: Richard Johanson, Academic Department of Obstetrics and Gynaecology, North Staffordshire Hospital NHS Trust, Newcastle Road, Stoke on Trent, ST4 6QG, UK. Tel: 01782 552483, Fax: 01782710936 , email: richard@kogs.freeserve.co.uk

(Accepted March 28 $\left.8^{\text {th }}, 2000\right)$

\begin{abstract}
Summary
This paper describes the development and pilot evaluation of a peer-produced video, produced for use as part of North Staffordshire's Personal and Social Education school programme. A number of studies carried out in the area, including a recent audit into post-coital contraception in the under $20 \mathrm{~s},{ }^{1}$ have shown that young people need to know how to access contraceptive services. Background surveys also suggest that young people need to be aware of the wider issues implicit in contraception.

The impetus for the video came from the Advice Centres for the under Twenties (ACT) Working Party, who produced the video together with Staffordshire University's Media Studies Department and a local high school drama group. The video was intended for use in schools, and was designed to be complimentary to an updated and standardised teaching pack, which was already in preparation.

The pilot study showed the video to be beneficial as a stand-alone intervention, principally to promote active discussion on topics that might otherwise be difficult to approach. A comparison of responses before and after the educational session demonstrated an improvement in knowledge in most areas. Further objective evaluation of the combined video and teaching pack is now necessary.
\end{abstract}

\section{Key words}

peer-led, sex education, teenage pregnancy, video

\section{Key message points}

- The UK has the highest teenage pregnancy rate in Western Europe, and teenage fertility is often associated with adverse social and physical outcomes for both mother and child.

- Trends in teenage pregnancy seem to be related to contraceptive service availability, but social attitudes to teenage pregnancy and abortion are also important.

- School-led peer education may be effective in reducing the teenage pregnancy rate, especially when linked to contraception services.

- Video has been used effectively in other areas of health education, and may be more effective when used within an integrated programme.

- A multidisciplinary group in North Staffordshire developed a peerled sex education video, which was piloted in a local youth club and a local high school. The video was of interest to students, providing both a source of information and a starting point for discussion.

- A complimentary teaching pack has now also been developed, and further evaluations of the combination of video and teaching pack now need to be undertaken.

\section{Introduction}

It is widely accepted that the UK has a higher teenage pregnancy rate than any other country in Western Europe, ${ }^{2}$ being seven times that of Holland, four times that of France and double that of Germany. Indeed, the UK now has one of the highest birth rates among unmarried teenagers in the Western World. ${ }^{3}$ The rate of teenage sexual activity has increased steadily and consistently over the past four decades. ${ }^{3}$

Teenage fertility is often associated with adverse social and physical outcomes for both mother and child. ${ }^{4}$ However, this is not necessarily the view portrayed by the media, where youthful pregnancy may be accorded glamour status by images of pregnant pop stars. 5

Trends in teenage pregnancy seem to be related to the availability of contraceptive services and access to reliable birth control. An increase in the incidence of teenage births is often seen following reports of the adverse side effects of contraception, with a slight effect persisting for 3-4 years afterwards. Social attitudes to teenage pregnancy and abortion, the provision of appropriate sex education, employment and educational opportunities and the availability of realistic alternative goals to motherhood, are all influential factors. ${ }^{4}$

A systematic review of teenage pregnancy found that school-based peer education is effective in reducing the teenage pregnancy rate, especially when linked to contraception services. ${ }^{2}$ Many strategies for an educational approach have been proposed ${ }^{6}$ such as abstinence programmes, ${ }^{7}$ vocational programmes to improve the overall education and job prospects for young people, and school-based building programmes. ${ }^{8}$ Most programmes have produced disappointing results. ${ }^{6}$ It would seem that for health education to be successful, it must be widereaching and more than simply a 'sharing of facts'. Indeed, it is well recognised that knowledge of 'risk' is largely irrelevant to teenagers' behaviour., 90

It has been shown that young people who have high selfesteem and self-confidence in their relationships are empowered to make their own decisions about sexual activity. Holland has the lowest teenage pregnancy rate in Europe, and it is no coincidence that under the Dutch educational programme, students begin their assertiveness training at 4 years of age. ${ }^{11}$

There is reassuring, consistent evidence that providing knowledge about sexuality and contraception does not lead to an increase in sexual activity and pregnancy. ${ }^{2}$ In fact, the opposite appears to be true, and experience in Holland has 
shown that the age of first sexual intercourse and pregnancy increased following the introduction of Personal and Social Education. ${ }^{12}$ A more recent survey from Finland has shown that easy access to contraceptive services and intensive sex education has not increased adolescent sexual activity. ${ }^{4}$

The government's Healthier Nation (formally Health of the Nation) strategy, launched in 1992, aimed to reduce the teenage pregnancy rate in the UK by $50 \%$ by the year $2000 .{ }^{13}$ Some initial progress was made in North Staffordshire, with the teenage birth rate dropping from $8.93 \%$ in $1993 / 94$ to $6.54 \%$ in $1995 / 96$. However, this rose again to almost $12 \%$ in 1997, possibly as a result of the 'Pill scare' of October 1995. Teenage mothers account for $20-30 \%$ of terminations at the North Staffordshire Hospital (Table 1).

\section{Background}

Several approaches have been developed in North Staffordshire in an attempt to reduce the rate of teenage pregnancy. These include the provision of easy access to contraceptive services, the audit of key areas and an ongoing contribution to school education programmes.

There are currently six ACT clinics in North Staffordshire, three located in health centres throughout the district, two in shopping areas and another near a smaller town centre. Two more clinics are planned. The ACT clinics have proved very popular, with attendance figures doubling between 1995 and 1998 despite their location in health centres. In addition to the ACT provision, all 23 family planning clinics (FPCs) welcome young people to their weekly or fortnightly sessions.

The North Staffordshire Hospital had already carried out a series of audits amongst both pregnant teenagers and attendees at family planning clinics, under the auspices of the Attaining Sustainable Quality in Women's Services (ASQUAWS) project. In 1996/97 the 'Post-coital contraception in the under 20s' audit found large gaps in the knowledge of post-coital contraception, and provided useful information about contraception failures. ${ }^{14}$ Another recent audit on post-coital contraception ${ }^{15}$ found that, although the majority of respondents were under 25 , only $1-2 \%$ had learnt about post-coital contraception at school.

Local educational approaches include 'Personal, Social and Health Education' programmes, with school nurse participation. These have been in place in most schools in North Staffordshire for the last 10 years. However, the teaching materials vary from school to school and both school nurses and teachers had expressed the need for additional resources (personal communication). The A-PAUSE project ${ }^{16}$ included an evaluated teaching pack, but it required more time to deliver than was available within the local school curriculum.

Video had already been used effectively in other areas of health education, and it had been suggested that it might be more effective if used within an integrated programme rather than as a stand-alone intervention. ${ }^{17}$ Many staff working in schools and clinics in North Staffordshire had previously utilised a video called 'No Worries'. This had been produced for young people, but it was made in the mid 1980 s and was outdated.

Given this background, the ACT Working Party (a multidisciplinary group made up of family planning doctors, nurses, midwives and a youth worker specialising in sexual health) aimed to pursue video as an intervention for achieving a reduction in the teenage pregnancy rate in North Staffordshire. Social learning theory has supported the development of peer-led teaching. ${ }^{10}$ Given the success of the A-PAUSE project, ${ }^{16}$ the group endeavored to include teenagers in the development of this new video project.

The video was intended for eventual use in conjunction with a teaching pack, which was already under development in collaboration with health educationalists and school nurses. The aim was that, when planning an educational session, the teacher/school nurse would simply select the most suitable material from the pack for the particular school's educational standard (including special needs).

\section{Method}

The impetus for the video came from the ACT Working Party. Staff and students from Staffordshire University's Media Studies Department and drama students from a local high school were approached and agreed to assist. The drama students were auditioned and divided into small groups. Each group was given a scenario to act out, and then these were filmed. In one example, a boy and girl acted out the scenario of 'visiting a clinic thinking that the girl may be pregnant'. They were both very enthusiastic about participating, and contributed many of their own ideas to the script.

The working party reviewed and edited the material and a final, more workable, script was developed using 'young peoples' jargon'. Each student was given a copy of the final script a week before filming began. Filming took place over 3 days, with one extra session for the voice recording of one-off sentences (to dub over disco scenes). The disco scenes themselves did not require any script but had directional requirements and were filmed at the school disco.

In summary, the video charts the progress of two groups of friends, boys and girls, in everyday life. It includes eight discussion breaks to give students the opportunity to ask questions or discuss issues. The key elements of relationships, sex, contraception and pregnancy are all discussed. It has a happy ending!

The video was shown to various family members, friends and colleagues (of all age ranges) for their reaction and comments. Minor changes to the script were agreed, two scenes were re-shot and credits were decided upon. The video was presented at a number of conferences, ${ }^{14,18}$ where it was very well received.

Table 1 Deliveries and terminations, North Staffordshire Hospital

\begin{tabular}{|c|c|c|c|c|c|c|}
\hline Year & All & $\begin{array}{l}\text { Deliveries } \\
\text { Under } 20 \mathrm{~s}\end{array}$ & $\%$ of all & All & $\begin{array}{c}\text { Terminations } \\
\text { Under } 20 \mathrm{~s}\end{array}$ & $\%$ of all \\
\hline ‘93-’94 & 5799 & 518 & $8.93 \%$ & 890 & 218 & $24.5 \%$ \\
\hline ‘94-’95 & 5744 & 401 & $6.96 \%$ & 899 & 200 & $22.2 \%$ \\
\hline ‘95-’96 & 5484 & 359 & $6.54 \%$ & 833 & 219 & $26.3 \%$ \\
\hline ‘96-’97 & 5707 & 539 & $9.45 \%$ & 904 & 264 & $29.2 \%$ \\
\hline ‘97-’98 & 5467 & 650 & $11.88 \%$ & 801 & 217 & $19.5 \%$ \\
\hline
\end{tabular}




\section{Pilot evaluation}

The video was piloted in a local youth club and a local high school. A questionnaire comprising 21 true or false statements was devised for evaluation. Additional questions were included on areas not specifically covered in the video but tackled during discussion breaks.

Piloting took place over three sessions, each run by the PEV co-ordinator and a local school nurse (who was also a member of the research group). A total of 75 teenagers aged 13-16 years (43 girls and 32 boys) were included. Following introductions, an explanation for the special session was given and students completed the pre-video questionnaire. Where students did not know the answer or were unsure, they were asked to leave the question blank. Questionnaires were completed independently, without asking friend's opinions or comparing answers. All questionnaires were anonymous, but were colour-coded by both group and gender.

Prior to the video being shown, it was explained that there would be frequent discussion pauses in which questions could be asked. Points raised in the discussion pauses were clarified to dispel any misconceptions. During each discussion pause, students were asked for their opinion on the content of the preceding scene.

\section{Results}

When the questionnaires were analysed, the total number of correct answers before the session was compared with the total number of correct answers after the session (for each question). The results are presented as percentages. Improvements in knowledge are shown in Figures 1-4. Results were calculated by gender and show a marked improvement in many areas of knowledge. This is especially apparent in the male group.

A number of interesting points were raised during the discussion breaks, and comments included:

- "It was easier to ask questions using the characters rather than being personal to me."

- "I felt more comfortable doing the session with the school nurse rather than a teacher; she is someone I would be happy to talk to if I needed advice."

- "It is good to be able to talk with the boys about things without arguing about who is right or wrong. We definitely understand more about each other now."

- "I like the video. There were things I have learnt about, that I would have been too shy to ask my mum or sister about. I will definitely not be frightened of going to the clinic when I need to."

\section{Discussion}

Lessons learnt from this video project echo the experiences of other researchers in this area. We found the teenagers to be enthusiastic, and they contributed many ideas to the project as it evolved. This supports the recent suggestion by Evans et $\mathrm{al}^{19}$ that a peer-led theatre-for-development model can be used in 'negotiating sexual intimacy' in the classroom.

We are optimistic that the positive and harmonious messages transmitted in the video about young peoples' control of their own fertility will, in conjunction with the provision of easily accessible and confidential services, eventually contribute to a fall in the teenage pregnancy rate in North Staffordshire. Clearly there will be a need for cooperation between the various sectors, and this spirit of co-
Figure 1 Increase in knowledge: Contraception

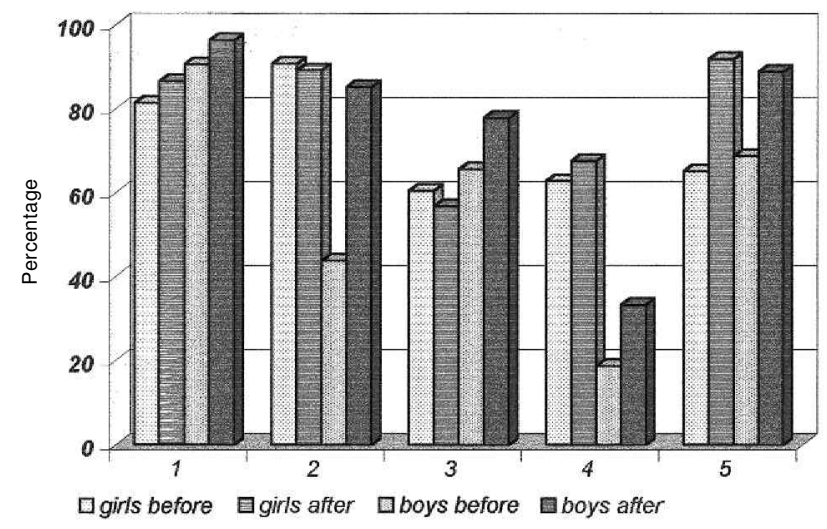

Figure 1 Questions

1. You can't get pregnant the first time you have sex (false)

2. Condoms help prevent sexually transmitted infections (true)

3. The pill can be a health risk (false)

4. Emergency contraceptive pills are a form of contraceptive (false)

5. A girl has 72 hours after unprotected sex to obtain one of the forms of emergency contraceptives (true)

operation is being fostered by the North Staffordshire Sexual Health Strategy. ${ }^{20}$

Nevertheless, it is essential that developing interventions are fully evaluated before they are widely introduced. This evaluation should be done with an agreed purpose and an acceptable methodology. ${ }^{10}$ Although knowledge, skills and self-confidence are important end-points, ${ }^{21}$ sexual activity, ${ }^{22}$ contraceptive uptake and pregnancy rates are particularly relevant. Wellings et $\mathrm{al}^{12}$ have emphasised the importance of carrying out prospective and randomised studies of the impact of sex education. The next stage in our project would therefore be to research the effectiveness of the video and teaching pack in a controlled study measuring (in addition to knowledge, skills and self-confidence):

1. The numbers of young people attending ACT and family planning clinics in North Staffordshire for a) contraception, b) emergency contraception, c) pregnancy tests

2. Numbers of young women attending for a) maternity care, b) termination of pregnancy

Figure 2 Increase in knowledge: Relationships

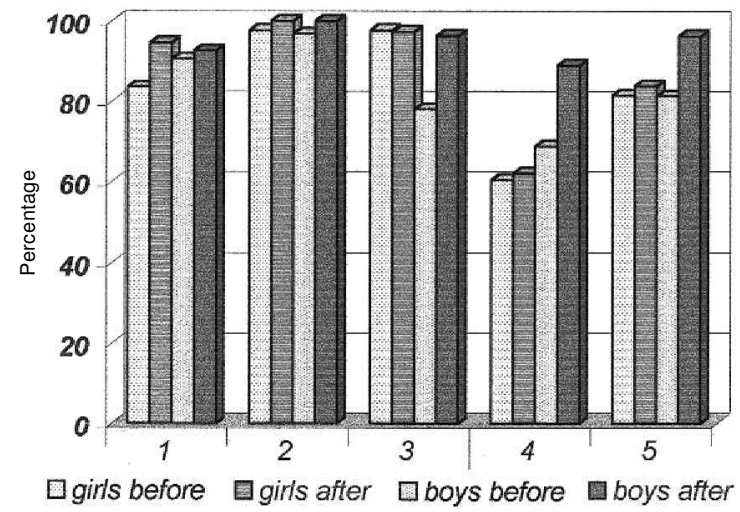

Figure 2 Questions

1. Girls may legally have sex under the age of 16 (false)

2. You should have sex to keep your boyfriend/girlfriend (false)

3. Sex is the most important part of a relationship (false)

4. Talking about sex is embarrassing (no correct or incorrect answer)

5. It is the girl's responsibility to obtain the contraception (false) 
Figure 3 Increase in knowledge: ACT and FP clinics

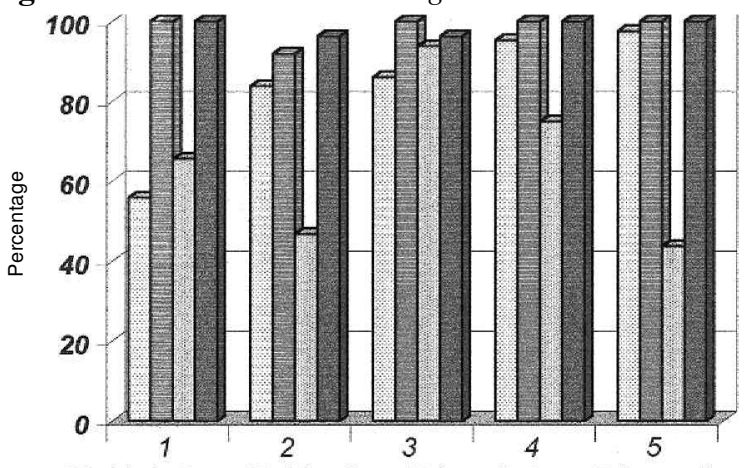

Egirls before $\square$ girls after $\square$ boys before - boys after

Figure 3 Questions

1. You have to be over 16 to attend a FP or ACT clinic (false)

2. Boys can attend FP and ACT clinics (true)

3. Pregnancy tests can be done in clinics (true)

4. Only boys can get condoms from FP or ACT clinics (false)

5. Contraceptives are free from FP and ACT clinics (true)

3. Uptake in the knowledge of a) the role of clinics, b) the use of contraception

4. Whether the teenage pregnancy rate is reduced in schools where this educational technique is used.

A 'cluster randomised study' would be a suitable design. ${ }^{23}$

\section{Conclusion}

This paper describes the background to, and development of, a peer-produced teenage pregnancy video. A pilot evaluation has already been carried out and the video was found to be of interest to students, providing a useful source of information and acting as a starting point for discussion. The video may be particularly helpful in promoting active discussion in what may otherwise be a difficult subject to tackle. Students found it easier to formulate and ask questions when these were based on characters in the video rather than on themselves.

Further refinement of the questions may be necessary and common misconceptions still need to be dispelled (see Figure 4).

The ACT Working Party has already begun the process of collating, updating and adapting material (in use in local schools) to create a teaching pack. The pack will provide information on personal, social, sexual and reproductive health for a wide range of pupils. The video is intended to be complimentary to the material contained in the pack, and further evaluations of the combination of video and teaching pack will need to be undertaken.

\section{Acknowledgements}

We would like to thank all those involved, without whom this project would not have been possible: Ray Johnson (Media Studies Department, Staffordshire University) and his students; Edensor High School Drama Group and their tutor, Mr Hadley; the ACT Working Party; Sister Tricia Wilkinson (Family Planning Midwife) for her comments and School Nurse Dawn Jennings for assistance with the pilot study.

\section{Statements on funding and competing interests}

Funding. The ASQUAWS project was funded by the West Midlands Regional Health Authority (LORS) and the North Staffordshire Hospital Trust. Mates International sponsored the video project. Senior Staff
Figure 4 Increase in knowledge: Popular misconceptions

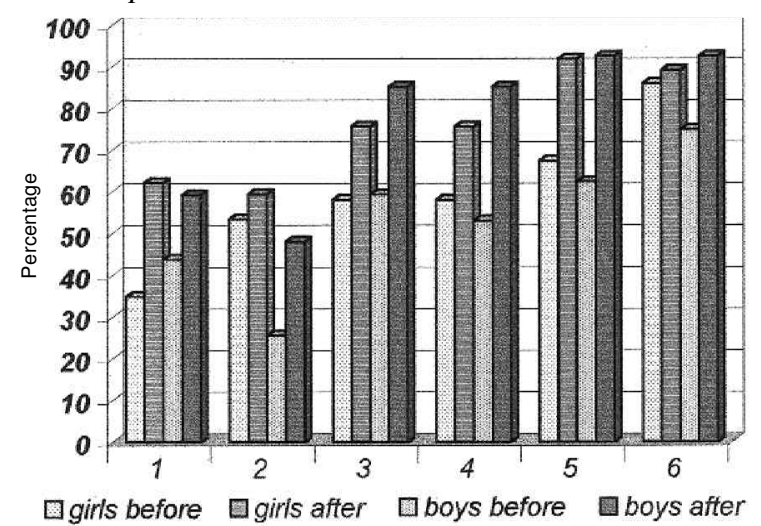

Figure 4 Questions

1. The pill helps to prevent sexually transmitted infections (false)

2. A girl can get pregnant while on the pill (true)

3. The only role of a FP and ACT clinic is to supply contraception (false)

4. You must have an appointment at the FP or ACT clinics (false)

5. Your GP must be told if you attend an FP or ACT clinic (false)

6. No information given by a young person at a clinic will be sent home or given to a GP without the young persons' permission (true)

Midwife Rita Butler generously gave her bursary to assist with funding of the video.

Competing interests. None. Although Mates International funded the video project, this paper does not specifically endorse any of their products.

The video and teaching pack are now available for sale. For information, please send all correspondence to Linda Lucking, Academic Department of Obstetrics \& Gynaecology, North Staffordshire Hospital NHS Trust, Newcastle Road, Stoke on Trent, ST4 6QG.

References

McGowan HC, Pedrazzini A, Johanson RB. Post Coital Contraception in the under Twenties. In: ASQUAWS Audit Report 1999, North Staffordshire Hospital Trust.

Dickson R, Fullerton D, Eastwood A, Sheldon T, Sharp F. Effective Health Care Bulletin Preventing and reducing the effects of unintended teenage pregnancies. NHS Centre for Reviews \& Dissemination, University of York: 1997.

Wellings $K$, Kane $R$. Trends in teenage pregnancy in England and Wales: how can we explain them? J R Soc Med 1999; 92: 277-282.

The independent inquiry into inequalities in health. London: HMSO, 1998.

The independent inquiry into inequalities in health. London: HMSO, 1998.
Heller Z. Pregnancy's new tyranny. Sunday Times, 1998 (13 December)

6 Kirby D, Shon L, Collins J, al. Schol bat Kirby D, Short L, Collins J, et al. School based programs to reduce

review of effectiveness. Public Healh Repors 1994, 109.339-360. ( say NO" enough? Family Relations 1990 (January); 39: 68-72.

: Impact of a new curriculum on sexual risk taking. Family Planning Perspectives 1991; 23: 253-263.

9 Nutbeam D, Macaskill P, Smith C, Simpson JM, Catford J. Evaluation of two school smoking education programmes under normal classroom conditions. BMJ 1993; 306: 102-107.

10 Mellanby AR, Phelps FA, Tripp JH. Sex education: more is not enough. Journal of Adolescence 1992; 15: 449-466.

Scott PR., Milsom GA., Milsom GL. Teachers and parents too - an assessment of Dutch sexual health education. Br J Family Planning 1995; 21: 20-21

12 Wellings K, Wadsworth J, Johnson AM, Field J, Whitaker L, Field B. Provision of sex education and early sexual experience: the relation examined. BMJ 1995; 311: 417-420.

3 Health of the Nation: a strategy for health in England. London: HMSO, 1992.

14 McGowan HC, Pedrazzini A, Johanson RB. Post coital contraception in the under 20s - part of ASQUAWS. J Clin Effectiveness 1998; 3: 31(Abstract).

15 Capper R. Audit of client knowledge of emergency contraception. North Staffordshire Combined Healthcare Trust. Primary Care Directorate 1999; 1-20.

16 Mellanby AR, Phelps FA, Crichton NJ, Tripp JH. School sex education: an experimental programme with education and medical benefit. BMJ 1995; 311: 403-406.

17 Eiser RJ, Eiser C. Effectiveness of video for health education: a review. London: HEA, 1997:1-100.

18 McGowan HC, Pedrazzini A, Johanson RB. Video presentation - "That's the trouble with sex..... it always gets in the way". Br J Obstet Gynaecol 1998; 105 (Suppl): 17.

19 Evans D, Rees J, Okagbue O, Tripp J. Negotiating sexual intimacy: A-PAUSE develops an approach using a peer-led, theatre-for-development model in the classroom. Health Education 1998; 6: 220-229.

20 Smith GE, Strategy Development Group. The Millennium and Beyond - towards a strategy fo Sexual Health in North Staffordshire. North Staffordshire Health Authority 1998:1-17.

21 Phelps FA, Mellanby AR, Crichton NJ, Tripp JH. Sex education: the effect of peer programme on pupils (aged 13 - 14 years) and their peer leaders. Health Education Journal 1994; 53: 127-139.

22 Tripp JH, Mellanby AR, Phelps FA, Curtis HA, Crichton NJ. A method of determining rates of sexual activity in school children. AIDS Care 1994; 6:453-457.

23 Donner A. Some aspects of the design and analysis of cluster randomization trials. Appl Statist 1998; 47:95-113. 